\title{
Entrevista a Laura Corral: Directora de la Escuela Primaria de la UNL
}

Nélida Barbach (1)

Martha Bolsi (2)

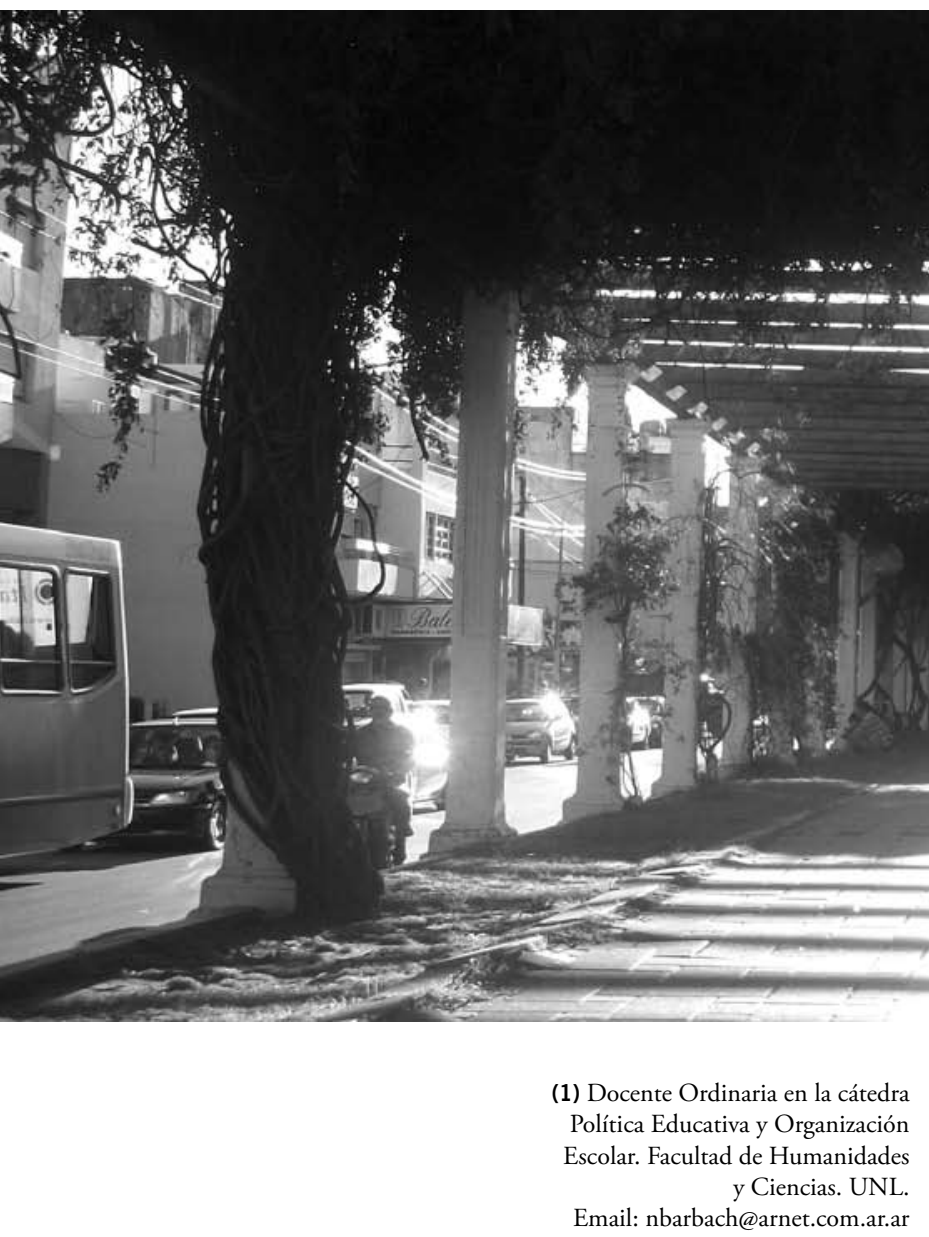

(2) Docente Ordinaria en la cátedra Psicología de la Educación.

Facultad de Humanidades y Ciencias. UNL.

Email:mbolsi@arnet.com.ar 
A través de la entrevista que se presenta a continuación se intenta proseguir con el relato sobre el desarrollo del Proyecto Educativo que se está llevando a cabo en la Escuela Primaria de la UNL. La parte inicial puede encontrarse en la revista Nro. 2, año 2, 2007 (pp. 63 a 68).

En la primera entrevista realizada a la directora de dicho establecimiento, Psicopedagoga Laura Corral, en esta misma publicación, Nro. 2, (pp. 63 a 68), quedaron pendientes temas de gran interés pedagógico-didáctico. Consideramos que la mejor forma de mostrar los resultados, era volver a darle la palabra. También a los docentes y a los alumnos (a través de sus producciones), partícipes activos del proyecto. De esta manera, se trata de volver a abrir un espacio de la revista para continuar con la difusión de esta interesante e innovadora experiencia educativa.
Nos dijo en esa oportunidad Laura Corral:

El proyecto Pedagógico de esta escuela se fundamente en su compromiso con la producción del saber y con la convicción de que quienes lo producen deben ser actores de ese saber. En consecuencia, proponemos una enseñanza que tiene por objeto no sólo un conjunto de conocimientos sino la apropiación por parte de los alumnos del quehacer que los produce. (p. 65) 


\section{¿Podrías explicar 0 ampliar la cita?}

Efectivamente, creo que la cita alude a una perspectiva fundamental del proyecto. Sabemos que uno de los problemas más complejos con los que nos enfrentamos cotidianamente es, a la par de la selección de contenidos, el de recuperar su significatividad y su potencia para generar comprensiones profundas.

Las reflexiones que se pueden hacer en este sentido son interminables. Cabe preguntarse, por ejemplo, por ciertos contenidos que se han hecho tradición en las escuelas pero por cuya importancia no respondería ninguna comunidad científica, o por la aplicación de recetas didácticas (enseñar de lo simple a lo complejo, o de lo cercano a lo lejano, por ejemplo) que van a contrapelo de la disciplina en cuestión y de la naturaleza misma de los procesos comprensivos.

Pero además la educación tradicional, en más de un aspecto y fundamentalmente en ciencias, ha tendido a ignorar el proceso de generación de las ideas, presentando un programa de contenidos escolarizados, totalmente disociados de la lógica del campo del conocimiento en el que fueron producidos.
Creemos que esto lleva a comprensiones frágiles y muchas veces erróneas, y que el desafío es generar una ruptura con el modo con el que la escuela presenta saberes que "son así", cristalizados, sin establecer relación alguna con autores, fuentes o corrientes interpretativas.

\section{¿De qué manera rompen ustedes con estas concep- ciones que podrían denominarse tradicionales?}

Nuestro proyecto implica, en este sentido, asumir la provisionalidad del conocimiento, en el diseño curricular y en la actualización de los debates que sostenemos como docentes, pero también como contenido mismo a enseñar. La perspectiva del conocimiento como constructo de determinada comunidad científica, en cierto contexto histórico, en relación de continuidad o de ruptura con otros conceptos o teorías previas, validado por una lógica intrínseca al campo que le dio origen y siempre provisorio es lo que permite que las nuevas generaciones se sitúen en la posibilidad de crear o recrear saberes, como agentes de su tiempo. 
Con sus matices para cada recorte disciplinar, esta es nuestra postura en todas las áreas. Estoy pensando en los debates que tenemos respecto del bicentenario, por ejemplo, en los que también nos planteamos la necesidad de que los chicos comprendan que conceptos como nación, patria, estado, república y tantos otros han sido construidos históricamente y que las distintas épocas los han pensado de modo diferente, pero es tal vez más evidente en el campo de las ciencias experimentales.

Creemos que para lograr una comprensión profunda del conocimiento científico es indispensable saber cómo se adquiere ese conocimiento, y en algún sentido reproducir ese proceso de construcción en el aula.

\section{¿Qué actividades se promueven a los efectos de lo- grar esa comprensión profunda a la que aludís?}

Se necesita promover en los chicos una intensísima actividad cognitiva, que implica partir de ideas preexistentes para confrontarlas, debatirlas, afianzarlas o desecharlas en pos de ir construyendo conceptos que, si bien son nuevos para ellos, han sido previamente validados por la ciencia.

Experimentar, formular hipótesis, ajustar las preguntas, dialogar e ir afinando los razonamientos para darles consistencia, aunque supongan el andamiaje del maestro, son procedimientos y características propios del pensamiento científico y reflejan en el grado el modo en el que los investigadores profesionales construyen este conocimiento.
Está claro que las particularidades de su pensamiento, por cuestiones evolutivas muchas veces y por falta de conocimientos previos muchas otras, hacen que las conclusiones a las que llegan los chicos sean parciales o atadas a prejuicios y esquemas todavía muy sólidos. Además de lo que ellos puedan descubrir, la necesidad de información pone en juego la sensibilidad del maestro para ir suministrando datos que permitan ir profundizando estos razonamientos, en su momento justo.

Nada, al fin, que no le pase a la ciencia misma. Si en la escuela no podemos pretender soluciones acabadas ni buscar la explicación total y la información completa sobre un tema, es necesario remarcar que tampoco lo hace la ciencia de los adultos. Y si no solo se pone en juego la creatividad y el descubrimiento activo, y son necesarios procesos receptivos de la información, también le sucede al científico enfrascado en la investigación más experimental cuando se vale de datos o saberes que no necesita inferir, y que ya le llegan organizados.

Entonces, nuestros alumnos no llegarán a ser científicos en la escuela primaria, por obvio que resulte, pero son capaces de asumir actitudes claramente científicas, de explicar satisfactoriamente algunos aspectos de la realidad, de incorporar y utilizar activamente conceptos científi$\cos$, de discutir e incluso verificar o desechar alguna teoría de su invención. Y estamos convencidos de que es el camino por el que debemos transitar para la construcción del conocimiento. 
Tal vez resulte interesante pensar estas cuestiones mirando de cerca un recorte concreto.

Creo poder afirmar que cualquiera de los proyectos de nuestra escuela, de primero a cuarto grado, daría cuenta de esta perspectiva de trabajo desde nuestra opción por el currículum integrado, pero pienso en uno en particular que puede ser muy gráfico.

Se trata de "A ciencia cierta y por amor al arte", proyecto que llevan adelante los terceros grados, diseñado el año pasado por los profesores Viviana Edsberg, Fabricia D’Ostuni, Adrián Martínez y Nancy Zurschmitten.

El corazón conceptual del proyecto es precisamente lo que venimos conversando, la visión de la ciencia no solo como producto (conocimiento científico) sino como proceso (quiénes, cómo, donde y cuándo se produce ese conocimiento), desechando la imagen que la asocia al descubrimiento de la verdad por la de una construcción social, y la de la divulgación como compromiso con la democratización del saber.

El tema comenzó planteando dos rincones en el aula, que en cierto modo contraponen la visión mágica a un pensamiento más riguroso. En el Rincón donde se esconden los deseos, por ejemplo se lee "Un Ramón, un salmón y tres deseos", de Graciela Montes, o se escriben las instrucciones para pedir un deseo cuando se nos cae una pestaña o sale la primer estrella, mientras que en el Rincón donde se coleccionan preguntas se lee "Martín Pensador" de Santiago Kovadloff y se ha- cen preguntas sobre la naturaleza. ¿Cómo se formó la tierra?, ¿De dónde salen los rayos?, ¿Qué es la electricidad?, ¿Por qué los dinosaurios no existen más?, ¿Hay vida en otros planetas?

El paso siguiente no se hizo esperar: ¿Existen respuestas para todas estas preguntas? ¿Quiénes trabajan para responderlas? Sobre la discusión de las primeras ideas de los chicos acerca de la ciencia, los científicos y las actividades que realizan se formularon algunas hipótesis, que debían ser investigadas.

Entonces visitaron la Facultad de Ciencias Hídricas y la Estación Meteorológica Experimental, trabajaron en los laboratorios de la Facultad de Bioquímica y Ciencias Biológicas y en el Parque Tecnológico conversaron con científicos del CONICET sobre la investigación en modelos de simulación, analizando los procedimientos y el instrumental que se utiliza en cada caso pero sobre todo apreciando la relación entre la actividad de cada científico con las preguntas que se formula.

También entrevistaron a Edith Litwin, asesora pedagógica de la escuela, en su carácter de investigadora, para trabajar la diferencia en las preguntas y los métodos de las ciencias sociales respecto de lo que venían pensando.

Todo esto fue permitiendo llegar a ciertas conclusiones:

- que todo científico para comenzar a investigar parte de un problema, de una pregunta; - que no todo problema es objeto de la ciencia ni toda respuesta es científica; 
- que los científicos intentan responder a sus preguntas mediante ciertos métodos;

- que hay preguntas con más de una respuesta posible;

- que las respuestas a una misma pregunta han ido cambiando en el tiempo, etcétera.

Después de todo este proceso de discusión y elaboración, acordando con Gardner en que una persona tendrá más probabilidad de pensar como científico si examina a fondo un tema concreto que si trata de asimilar cien ejemplos diferentes provenientes de cien campos distintos, el proyecto propone una sola pregunta fundamental.

Desde la perspectiva de enseñanza, aprendizaje, curriculum, que ustedes plantean, qué recortes de contenidos en particular se eligió en relación al conocimiento científico?

El año pasado, haciendo pie en que era el año darwiniano, la pregunta fue ¿De dónde venimos? Este año, tomando un recorte no de biología sino de física, la pregunta será por el movimiento. Y el desarrollo levará a un momento de la historia de la ciencia en el que no hay una ruptura como la que produjo Darwin sino cierta continuidad y formalización de las respuestas, en el eje Galileo Galilei-Newton.

Voy a contarles un poco el trabajo del año pasado, que ya está concluido, pero me parece interesante subrayar este aspecto del modo en el que pensamos los proyectos, y éste en particular. Delimitamos el recorte fundamental que nos interesa trabajar, desde todas las áreas (porque todavía no hablamos de esto pero están pensados también los contenidos de lengua, de inglés, de ciencias sociales, de matemática, etc. que se van a articular) y nos proponemos que se mantenga en el tiempo, pero hay todo un cuerpo de contenidos que son periféricos a este eje y que seguramente van a ir cambiando año a año. También cambiarán las estrategias, por lo tanto, y la física newtoniana implicará más actividades experimentales que la evolución de los seres vivos.

Pero, en cualquier caso, el fuerte del proyecto y la perspectiva desde la que se lo trabaja son los mismos. Ni Darwin ni Newton son la cuestión, digamos, aunque el producto del proyecto sea una revista de divulgación cuyos dos primeros números se centren, respectivamente, en ellos.

\section{¿Qué conceptos centrales se investigaron desde las nuevas propuestas de contenidos. Qué actividades desarrollaron? \\ Volviendo al desarrollo del año pasado, formu- lada la pregunta ¿De dónde venimos? se abrie- ron muchos caminos, que remontaron los inten- tos del hombre por responderla. En las precon- cepciones de los chicos aparecieron cuestiones religiosas, lo que dio lugar a lecturas y búsque- das por las historias que fueron creando las dis- tintas civilizaciones.}


Así, a partir de "El mito olímpico de la creación", de Robert Graves, elaboraron el árbol genealógico de los dioses griegos y descubrieron que Gea y Cronos se encontraban en la raíz de numerosas palabras que buscaron y agregaron a su diccionario. "Prometeo y el fuego divino" abrió no solo a nuevos dioses sino a dos obras de arte que enriquecieron el tema desde otro lenguaje: la de Rubens, de 1612, con Prometeo robando el fuego divino, y la de Dirik van Baburen, casi contemporánea, que lo muestra encadenado por Vulcano.

También investigaron sobre mitos mayas y tehuelches, realizando actividades de escritura y de producción gráfica, y todo ese material les permitió ir sacando conclusiones colectivamente. Por ejemplo,

- que los mitos son historias antiguas;

- que se inventaron para dar explicaciones o respuestas a aquellas preguntas que se hacían los hombres y que no se podían responder de otro modo;

- que se transmitieron de boca en boca y de generación en generación, como relatos orales; que sus personajes son Dioses y Héroes que poseen poderes extraordinarios;

- que para los griegos Prometeo creó al hombre, para los esquimales Papá Cuervo, para los mayas El Formador y el Creador y para los tehuelches Kóoch;

- que por lo tanto, para las religiones y los mitos la vida es creación de los dioses.
Este intenso trabajo les permitió también ir construyendo dos conceptos fundamentales y polémicos: hay ideas creacionistas sobre el origen del hombre y de los seres vivos (creacionismo), que suponen además que fueron creados tal como los conocemos ahora (fijismo). Y si hasta ese momento ya se habían desatado discusiones, la aparición de Cuvier y su teoría de las catástrofes significó una verdadera revolución.

Llegaron al padre de la paleontología por la misma vía que lo hizo en su momento la ciencia, cuestionando la evidencia que suponen los fósiles. Es innegable que los dinosaurios forman parte del universo de los niños, lo que los acerca tempranamente a ideas respecto de la paleontología y la extinción de ciertas especies. De modo que investigar en la fosilización (por momificación, por inclusión o por impresión) y precisar las características de la paleontología como ciencia de algún modo fue una profundización de esos saberes previos.

El terreno estaba preparado para las discusiones más fecundas, y con el conocimiento de los aportes más importantes de George Cuvier los chicos tuvieron elementos para relanzar su pregunta: ¿por qué los restos que se encuentran no se corresponden con ninguna especie existente hoy? Si Dios creó de una sola vez todas las especies, ¿por qué no se encuentran fósiles de las especies que hoy vemos?, ¿y qué pasó con esas especies de hace millones de años?

Cuando los maestros introdujeron, ahora sí, la Teoría de las Catástrofes, los chicos ya habían 
formulado todo tipo de hipótesis, intentando responder tantos interrogantes. Y la teoría de Cuvier no terminaba de convencerlos, como respuesta, pero la pregunta se enriqueció considerablemente. El fijismo ya no parecía ser la opción, era poco probable que todo se hubiera destruido $y$ vuelto a crear.

La idea de evolución asomaba en el horizonte, pero cobró su verdadera dimensión con Lamarck y la disputa con Cuvier por la herencia de caracteres adquiridos. Su ejemplo del proceso evolutivo de la gacela a jirafa fue analizada desde todos los ángulos, y cuestionada desde el saber más cotidiano ("si tu mamá se opera y se pone...lolas... ivos no vas a salir con lolas grandes como las que se puso!", "mi mamá se tiñe, pero yo no tengo el color del pelo teñido")

Así, el clima que recibió a Darwin en el aula se asemejaba mucho al de las disputas de su tiempo. ("¿Vos qué sos, fijista o evolucionista?")

Los chicos investigaron sobre su biografía y su formación, salieron como él a buscar en la naturaleza insectos para observar y clasificar, aprendieron distintos criterios de clasificación que se dieron en la historia (Aristóteles, Linneo, etc.), en inglés siguieron el recorrido de su viaje en el Beagle y conocieron las especies con las que se encontró y la geografía y el clima de los lugares por los que pasó.

También se internaron, leyendo el de Darwin, en lo que implica la escritura de un Diario. $Y$ con sus cartas, en la comunicación epistolar. Leyeron la invitación de Henslow para que se embarcara en la expedición que lo haría famoso, y le escribieron ellos mismos argumentando las razones por las que debía aceptar (iy Darwin hasta les contestó, en cartas que esperaba toda la escuela!)

También escribieron descripciones y cartas en inglés, que despacharon por correo a familiares $o$ amigos.

La tarea obligada por la suspensión de clases por la epidemia de gripe H1N1 propuso lecturas y ficciones en las que se embarcaban con Darwin y debían solucionar desde cuestiones prácticas, como calcular los víveres para la expedición, hasta el encuentro con aborígenes fueguinos a los que debían conocer, investigando, para poder interactuar.

Respecto de lo central del pensamiento darwiniano, las ideas de selección natural y de supervivencia del más apto se construyeron a partir de un juego de simulación en el que los chicos tenían que ponerse en el lugar de predadores que cazaban aves de distintos plumajes, representadas por fichas amarillas o negras, en un corto tiempo, sobre un fondo amarillo. Si solo se puede cazar de día, ¿qué presa resulta más fácil de capturar? Con el tiempo, ¿qué especie tiene más posibilidades de sobrevivir?

Formulados colectivamente estos principios fueron contrastados con la realidad, por ejemplo imaginando las características que deberían tener los animales más aptos para vivir en climas fríos, o los de hábito nocturno, y luego verificando si esto se daba como lo habían supuesto. 
Pero además Charles Darwin supuso, para la historia de la ciencia tanto como para el pensamiento de nuestros alumnos, un cambio de paradigma. De pronto, el hombre no era más el centro de la creación sino una rama más del árbol de la vida, pariente del pájaro y de las estrellas de mar, parte de todo lo vivo. Es difícil de trasmitir el impacto que estas ideas generaron en niños de ocho años, el modo en que cada uno tomó partido a nivel de la opinión personal o se las ingenió para formular teorías que conjugaran la fe en la creación con la evidencia de la evolución.

Y creo que el producto da cuenta cabal de todo este proceso.

\section{Hiciste mención a una revista editada por los mis- mos chicos. ¿Qué cuestiones se consideraron para su edición?}

La idea era la edición de una revista de divulgación, para la cual trabajaron paralelamente durante todo el proyecto. Analizaron publicaciones de divulgación científica y trabajaron con Romina Kippes, directora de comunicación institucional de la Universidad y editora de ConCiencia, para conocer las características de revistas de este tipo.

A través de juegos trabajaron en taller el formato textual de la divulgación científica, comparándolo con el de otros tipos de texto, y produjeron absolutamente todos los escritos que componen la revista. Redactados en algunos casos individualmente y en otros en pequeños grupos, la innumerable cantidad de originales se corrigieron y se ajustaron colectivamente hasta llegar a los artículos que se publicaron. Supongo que es imaginable el trabajo que hay detrás del acuerdo de un texto único a partir de veinticuatro originales de autores de ocho años.

También propusieron y eligieron el nombre para la revista, que desde ese primer número se llama Esciencia - grandes preguntas pensadas con chicos, entrevistaron a Federico Giri, biólogo de nuestra Universidad y docente de la cátedra de evolución, y hasta escribieron la editorial.

No tengo dudas de que la publicación es enormemente más atractiva que mi tediosa descripción, aunque me haya resultado inevitable contar con cierto detalle la intensa actividad que implicó el desarrollo del proyecto.

Seguramente habría podido optar por mencionar que conocieron el planisferio y la línea del Ecuador, que ubicaron las Islas Galápagos y el exoesqueleto de los invertebrados o la adaptación de los seres vivos al medio como contenido de ciencias naturales. Pero ese camino no hubiera dado cuenta del modo en el que jugando, haciendo fósiles de yeso, entrevistando a científicos, leyendo, discutiendo y dibujando estos alumnos de ocho años pudieron construir ciertas diferencias entre el pensamiento mítico y el científico, y una visión de la ciencia como construcción con continuidades y rupturas. 
De todos modos, es en lo que ellos dicen y preguntan en la revista donde podemos evaluar los aprendizajes que se dieron. Preguntan por los desarrollos posteriores a Darwin, concientes de que seguramente se siguió pensando en estos temas, preguntan por el método de investigación y por opiniones personales del entrevistado, preguntan si Darwin fue muy importante para la historia de la ciencia. En la editorial dicen que cuando uno sabe algo lo tiene que publicar "para que otros lo conozcan, porque es importante, y para que lo critiquen o no", cuentan de sus discusiones y del proceso de escritura y concluyen en que "Darwin revolucionó a la ciencia pero sigue siendo polémico. Porque se sabe que todo evolucionó, pero todavía no se sabe cómo".
Afortunadamente, a posteriori de su edición en papel, que contó con el apoyo del Programa de Difusión de la Ciencia de nuestra Universidad y fue presentada hasta en la Feria del Libro, la revista se digitalizó para incluirla en el blog de la escuela y se puede visitar. Les sugiero darle una miradita en http://unlescuelaprimaria.blogspot.com/

Tu compromiso y entusiasmo por contar esta experiencia es tal que permite imaginar el camino que están recorriendo. Hay un gran trabajo creativo y colaborativo de la comunidad educativa en esta ardua y apasionante tarea de contribuir a la formación de alumnos pensantes. 